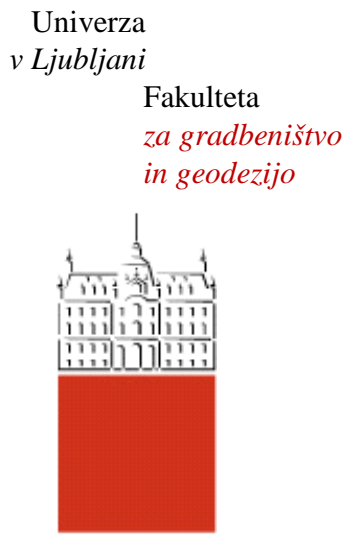

Jamova 2

1000 Ljubljana, Slovenija http://www3.fgg.uni-lj.si/

DRUGG - Digitalni repozitorij UL FGG http://drugg.fgg.uni-lj.si/

Ta članek je avtorjeva zadnja recenzirana različica, kot je bila sprejeta po opravljeni recenziji.

Prosimo, da se pri navajanju sklicujete na bibliografske podatke, kot je navedeno:

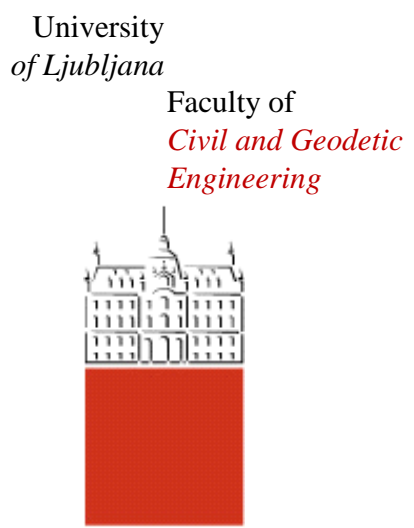

Jamova 2

SI - 1000 Ljubljana, Slovenia http://www3.fgg.uni-lj.si/en/

DRUGG - The Digital Repository http://drugg.fgg.uni-lj.si/

This version of the article is author's manuscript as accepted for publishing after the review process.

When citing, please refer to the publisher's bibliographic information as follows: 6: 849-855.

DOI: 10.1016/j.autcon.2009.03.009. 


\title{
New numerical procedure for prediction of temperature development in early age concrete structures
}

\author{
Anka Ilc $^{\mathrm{a}, \mathrm{b}}$, Goran Turk ${ }^{\mathrm{a}, *}$, Franci Kavčičc ${ }^{\mathrm{c}}$, Gregor Trtnik ${ }^{\mathrm{a}, \mathrm{c}}$ \\ ${ }^{a}$ University of Ljubljana, Faculty for Civil and Geodetic Engineering, Jamova 2, SI-1115 \\ Ljubljana, Slovenia \\ ${ }^{\text {b} P r i m o r j e ~ d . d ., ~ V i p a v s k a ~ c e s t a ~ 3, ~} 5270$ Ajdovščina, Slovenia \\ ${ }^{c}$ IGMAT d.d., Building Materials Institute, Polje 351c, Ljubljana, Slovenia
}

\begin{abstract}
A new numerical model for prediction of temperature development in young concrete structures is briefly presented. This program consists of a pre-program and main program. With the preprogram, adiabatic hydration curves, which are used to determine the internal heat generation, are calculated. An artificial neural networks approach is used for this purpose. Adiabatic hydration curves, which were included in the learning set, were determined by our own experiments, using the adiabatic calorimeter which uses air as the coupling media. The main program is implemented in the finite element code. This program allows concrete structure designers and contractors to quantify and evaluate the effects of some concrete initial parameters on the adiabatic hydration curves and corresponding temperature development at an arbitrary point in the concrete element. Some examples are also presented and discussed.
\end{abstract}

Keywords: Young concrete; Adiabatic calorimetry; Adiabatic hydration curves; Artificial neural networks; Maturity, Finite element method.

\section{Introduction}

Hydration process in hydrating concrete is a complex phenomenon, which is influenced by many factors. These factors have to be accounted for, since they could influence the heat development, and thus the development of thermal stresses in concrete structures at early ages. The interaction of these factors is very complex. The cement composition, initial concrete temperature, amount of cement, water-cement ratio, presence of mineral and chemical

\footnotetext{
${ }^{*}$ Corresponding author. Phone: +386 14768 614; fax: +386 14768629

Email address: gturk@fgg.uni-lj.si
} 
admixtures, etc., primarily influence the heat of hydration process in concrete structures. The hydration process is also strongly affected by its current temperature and moisture content. Therefore, ambient air temperature, wind speed, relative humidity, solar radiation, and cloud cover, cause the hydration behaviour in field conditions to be very different from hydration under laboratory conditions.

The hydration process of cement in concrete in laboratory conditions is usually the basis for further prediction of behaviour of concrete in structures. Development of hydration processes in qualitative respect may be followed by monitoring the development of hydration heat by direct or indirect methods. Adiabatic heat measurements would be the most precise for producing continuous heat of hydration curves under curing conditions close to or almost identical to mass curing. Therefore, adiabatic hydration curves would be the most suitable starting point for temperature calculations in hardening concrete structures.

A number of models have been proposed to predict the heat evolution and resulting temperature development characteristics in concrete during the early ages of hydration process. Such computer programs are based on finite difference [1] or finite element $[2,3,4]$ method. The development of temperatures in hydrating concrete is usually determined from the transient heat balance, as governed by Fourier's law

$$
\rho c_{p} \frac{\partial T}{\partial t}=\frac{\partial}{\partial x}\left(k_{x} \frac{\partial T}{\partial x}\right)+\frac{\partial}{\partial y}\left(k_{y} \frac{\partial T}{\partial y}\right)+\frac{\partial}{\partial z}\left(k_{z} \frac{\partial T}{\partial z}\right)+Q
$$

and boundary and initial conditions, for example

$$
\begin{array}{ll}
k_{i j} T_{j} n_{i}+h\left(T-T_{A}\right)=0 & \text { (where the heat flux is prescribed) } \\
T=T_{P} & \text { (where the temperature is prescribed) } \\
T\left(x_{i}, 0\right)=T_{\text {init }}\left(x_{i}\right), &
\end{array}
$$

where $\rho, c_{p}$ and $k_{i}(i=x, y, z)$ are the density, specific heat and thermal conductivity of concrete, respectively. In these equations, $T=T(x, y, z, t)$ is the temperature in a concrete structure at point $x_{i}=(x, y, z)$ at time $t$ and $Q$ states for the internal heat of hydration which can be determined by adiabatic hydration curve. In Eq. (2-4), $h, T_{A}, T_{P}$, and $T_{\text {init }}$ denote the heat transfer coefficient, 
ambient temperature, prescribed temperature at the boundary, and prescribed initial temperature at point $x_{i}$, respectively.

Several empirical equations have been proposed to predict the adiabatic hydration curves, i.e. the adiabatic temperature rise $T_{a}(t)$ of concrete mixture $[5,6,7,8]$. The main disadvantage of these equations is that the empirical coefficients have to be determined experimentally and specifically for each concrete mixture. This is time consuming and hence expensive. Ballim's model [1] incorporates the result of a rate of heat evolution determination using a low-cost adiabatic calorimeter for individual concrete mixture. It would be of great advantage if these adiabatic curves could be generated by adequate numerical models.

Some numerical models exists, which are able to predict the adiabatic hydration curve for an arbitrary concrete mixture $[8,9,10]$. Evsukoff et al. presented a data mining approach for modelling the adiabatic temperature rise during cement hydration [11].

In this paper, a new computer program for predicting the temperature profile in concrete structures at early age is presented. The main advantage of this program is that the adiabatic hydration curves can be very reliably determined for an arbitrary concrete mixture. For this purpose a special program is prepared, which is able to determine the adiabatic hydration curve by artificial neural network, using the following parameters: the initial concrete temperature, amount of cement, type of cement, water-cement ratio, and some concrete admixtures. Adiabatic hydration curves, which were used in learning procedure, were determined experimentally in our laboratory. Adiabatic calorimeter which uses air as a coupling media was employed. The adiabatic hydration curve which is determined by this special pre-program is implemented into a main program for determination of a temperature profile in an arbitrary concrete structure. This program is based on finite element code and uses a heat rate-maturity relationship to determine the rate of heat of hydration at various times and locations in the concrete element [1]. The apparent activation energy, which plays the main role in the wellknown Arrhenious maturity equation, was determined according to the procedure, proposed by Morabito [5]. Several initial and boundary conditions, namely radiation, convection, constant or variable temperature at the element boundary, as described in [1], are included in this model. 
Also, several models to determine the specific heat and thermal conductivity of concrete are built in $[12,13]$. Finally, some results are briefly presented and discussed.

\section{Determination of adiabatic hydration curve}

\subsection{Experimental work}

To achieve the objective of this study, 24 adiabatic tests were performed. The influence of cement type, $C T$, water cement ratio, $W C$, amount of cement, $A C$, some concrete admixtures, $C A$, and initial concrete temperature at the adiabatic hydration test, $T_{0}$, on the hydration process and thus adiabatic hydration curves were investigated. Adiabatic calorimeter of IGMAT Building Materials Institute, which uses air as the coupling media, was used. Adiabatic temperature rise was recorded automatically on PC. The duration of one test was about 168 hours. Fig. 1 and Table 1 present some measured adiabatic hydration curves, used in this study. Within this study, cement type was descibed by the amount of ultimate heat of hydration of the cement, $H_{c e m}[\mathrm{~J} / \mathrm{g}]$.

Table 1

A method of estimating the maximum heat of hydration of cement is to determine the percentage of the total mass of each constituent and multiply these by the heat of hydration of the respective components as shown in Eq. 5.

$$
H_{c e m}=\sum h_{i} p_{i},
$$

where $h_{i}$ stands for the heat of hydration of individual $i$-th component $[\mathrm{J} / \mathrm{g}]$ and $p_{i}$ stands for the mass ratio of $i$-th component of the total cement content. Table 2 presents the values of $H_{c e m}$ for all cements, used in this study.

Table 2

Fig. 1 


\subsection{Artificial neural networks}

There are many applications of artificial neural networks (ANNs) in concrete structures. Some years ago, there have been reports on the use of ANNs in the modelling of concrete strength $[14,15,16]$, but recently ANNs have also been efficiently used for the prediction of concrete compressive strength based on various non-destructive tests $[17,18,19]$, compressive strength of concrete with some admixtures [20], and some other properties of concrete [21]. Artificial neural networks are networks, consisting of several very simple elements, called neurons. The connections between neurons are defined by their weights. Through connections a neuron receives signal from other neurons. The multi-layer feed-forward neural networks are usually employed as the approximators of an unknown functional relationship. The input units, which represent the input data, are connected to the first layer of hidden units, which are further connected to the units of the next hidden layer. The units of the last hidden layer are connected to the output units, which represent the output data. Each unit is represented by its value $y_{i}^{k}$.

Each connection between units is characterized by its weight $w_{i j}^{k}$. The index $i$ corresponds to the unit number of $k^{\text {th }}$ layer, while index $j$ corresponds to the unit number of the $(k-1)^{\text {th }}$ layer. The value of a unit is multiplied by the corresponding weight and added to the value of the signal in the unit of the next layer. In addition, the value of bias neuron or threshold $\vartheta_{i}^{k}$ is added to the equation

$$
y_{i}^{k}=f\left(\sum_{j=1}^{n_{k}-1} w_{i j}^{k} y_{k}^{k-1}+\vartheta_{i}^{k}\right) \text {. }
$$

In equation (6), $f($.$) stands for the activation function which enables modelling of an arbitrary$ continuous non-linear relation between input and output variables. A set of known input and output values is termed an input-output pair. All pairs are divided into two sets. The first one is termed as the learning or training set, which is used to determine the weights $w_{i j}^{k}$. When the learning procedure ends, the performance of the neural network is assessed on the testing data. The training procedure is, in fact, a general optimization problem in which the minimum of error $E_{p}$ is sought 


$$
E_{p}=\frac{1}{2} \sum_{i=1}^{n_{0}}\left(T_{p i}-y_{p i}^{n_{l}}\right)^{2}
$$

where $T_{p i}$ are the actual or target output values, $y_{p i}^{n_{l}}$ are the values of neurons in the output layer $n_{l}$, i.e. the output value obtained by $\mathrm{ANN}$, and $n_{0}$ is the number of neurons in the output layer.

\subsection{Construction of ANN model for adiabatic hydration curves - construction of pre-program}

The input layer was modelled with six input neurons, corresponding to the five influencing factors, namely cement type, amount of cement, w/c ratio, initial concrete temperature, amount of additive, and time $t$. The output layer was modelled with one output neuron corresponding to the adiabatic temperature rise $T_{a}$. Many calculations with different geometries of ANNs were carried out. On the basis of the results, the final solution was obtained by ANN having geometry 6-30-30-30-1 - i.e. there were 3 hidden layers, each of them included 30 neurons. Different sizes of learning and testing sets were tried; however, the results did not differ considerably. Finally, about $75 \%$ of randomly selected pairs $\left(t_{i}-T_{a i} ; i \approx 40000\right)$ were used for learning and the remaining $25 \%$ were used as testing pairs. The efficiency of the learning procedure was very good. The coefficient of correlation between the actual (target), $T_{a, e x p}$, and calculated, $T_{a, A N N}$, values of adiabatic temperature rise was $R^{2}=0.9969$. When all the weights $w_{i j}^{k}$ were determined, a numerical subroutine was implemented into the Matlab programming environment to evaluate the adiabatic temperature rise at time $t$ for arbitrary values of factors.

\subsection{Adequacy of the proposed model}

In order to asses the adequacy of the proposed model, two studies have been done. These studies are briefly described in the following paragraphs.

2.4.1 Study 1: Approximation of some adiabatic hydration curves with this model 12 adiabatic hydration curves, which were used in learning set, were randomly chosen in order to establish the ability of the proposed model to approximate these adiabatic curves. The average coefficient of correlation was $R^{2}=0.9986$. 
2.4.2 Study 2: Sensitivity of the proposed model to predict new adiabatic hydration curves Several examples were done in order to check the sensitivity of the proposed ANN model to predict new adiabatic hydration curves. The effects of concrete initial parameters were in accordance with the well-known rules of mix proportioning and other initial characteristics of fresh concrete mixture. In some cases, none of the input parameters had extreme value with respect to parameter values of all other curves, which were included in the learning set. The ability of ANN model to predict new curves was very good in this case. On the other hand, examples were also done, where one or more input parameters had extreme values with respect to parameter values of all other curves, which were included in the learning set. In those cases, the accuracy of the proposed model was slightly lower. This indicates, that ANN has good capability for interpolation, and is not as efficient in the case of extrapolation. Detailed description of this phenomenon can be found in [22].

\section{Development of the heat model - main program}

\subsection{Basic equation}

For clarity, a basic introduction to the finite element method (FEM) used in this analysis is briefly presented below. Eq. (1) can be written in the discretized form of the FE method as

$$
(\mathbf{K}+\mathbf{H}) \mathbf{t}+\mathbf{C t}_{\mathbf{t}}=\mathbf{f}
$$

where $\mathbf{K}, \mathbf{H}, \mathbf{C}$, and $\mathbf{f}$ are global conductivity matrix, global heat transfer matrix, global capacity matrix, and global load vector, respectively, and $\mathbf{t}_{\mathbf{t}}$ is the time derivative of

temperature $\mathbf{t}$. In Eq. (8), $\mathbf{K}$ is an assemble of element conductivity matrices $\mathbf{K}_{\mathbf{e} i}, i=1 \ldots N$, $\mathbf{H}$ is an assemble of element heat transfer matrices $\mathbf{H}_{\mathbf{e}_{i}}, i=1 \ldots N$, and $\mathbf{C}$ is composed of element capacity matrices $\mathbf{C}_{\mathrm{e}_{i}}, i=1 \ldots N$. Element matrices are evaluated by the following equations:

$$
\begin{aligned}
& \mathbf{K}_{\mathbf{e} i}=\int_{V_{e}} \mathbf{B}^{T} k \mathbf{B} d V, \\
& \mathbf{H}_{\mathbf{e} i}=\int_{S_{e}} \mathbf{N}^{T} h \mathbf{N} d S,
\end{aligned}
$$




$$
\mathbf{H}_{\mathbf{e}_{i}}=\int_{S_{e}} \mathbf{N}^{T} \rho c_{p} \mathbf{N} d V
$$

In Eq. (9), $\mathbf{B}$ stands for the derivatives of the shape function matrix $\mathbf{N}$ with respect to Cartesian coordinates. Load vector $\mathbf{f}$ is expressed as

$$
\mathbf{f}=\mathbf{r}_{\mathbf{q}}+\mathbf{r}_{\mathbf{Q}}+\mathbf{r}_{\mathbf{h}}
$$

where $\mathbf{r}_{\mathbf{q}}, \mathbf{r}_{\mathbf{Q}}$ and $\mathbf{r}_{\mathbf{h}}$ are global vectors, which take into account the radiation, internal heat generation and convection, respectively. Vector $\mathbf{r}_{\mathbf{q}}$ is assembled from element vectors $\mathbf{r}_{\mathbf{q e}}$, vector $\mathbf{r}_{\mathbf{Q}}$ is assembled from element vectors $\mathbf{r}_{\mathbf{Q e}}$ and vector $\mathbf{r}_{\mathbf{h}}$ is assembled from element vectors $\mathbf{r}_{\text {he }}$, where

$$
\begin{aligned}
& \mathbf{r}_{\mathbf{q e}_{i}}=\int_{S_{e}} \mathbf{N}^{T} q_{B} d S, \\
& \mathbf{r}_{\mathbf{Q e}_{i}}=\int_{V_{e}} \mathbf{N}^{T} Q d V, \\
& \mathbf{r}_{\mathbf{h e}_{i}}=\int_{V_{e}} \mathbf{N}^{T} h T_{f} d V .
\end{aligned}
$$

In Eq. (13-15), $q_{B}, Q, h$ and $T_{f}$ are prescribed heat flux normal to surface $\left(\mathrm{J} / \mathrm{m}^{2} \mathrm{~s}\right)$, rate of internal heat generation per unit volume due to cement hydration $\left(\mathrm{J} / \mathrm{m}^{3} \mathrm{~s}\right)$, heat transfer coefficient, or film coefficient $\left(\mathrm{J} / \mathrm{m}^{2} \mathrm{~s}^{\circ} \mathrm{C}\right)$, and surrounding temperature $\left({ }^{\circ} \mathrm{C}\right)$, respectively. $V_{e}$ and $S_{e}$ denote the element volume and element surface, respectively.

\subsection{Determining the rate of internal heat evolution $Q$}

As stated in previous sections, internal heat evolution is a very important parameter in the transient heat balance equation (Eq. (1)) when dealing with concrete structures at early age. The heat liberated in adiabatic conditions at time $t$ can be determined from continuous measurements of the relative adiabatic temperature rise $T_{a}(t)$ and is expressed as

$Q_{a}(t)=T_{a}(t) \rho c_{p}$

As in the case with the most chemical reactions, the hydration of cement and thus the liberated heat of hydration is strongly affected by its current temperature and moisture state. 
Environmental conditions causes the hydration behaviour under field conditions to be very different from hydration under laboratory conditions. The maturity method is an approach used to account for the combined effect of temperature and time on the development of concrete mechanical properties and the development of hydration. These effects can be quantified on the basis of the well known Arrhenious maturity function $f_{A}$ (Eq. 17), in which the temperature sensitivity factor is given by the apparent activation energy $E_{A}$ which is a function of the temperature and the degree of hydration.

$$
f_{A}\left(T, Q_{a}\right)=\exp \left(-\frac{E_{A}}{R}\left(\frac{1}{T}-\frac{1}{\left(\frac{Q_{a}}{\rho c_{p}}\right)+T_{0}}\right)\right)
$$

In Eq. (17), $R$ denotes the gas constant $(R=8315 \mathrm{~J} /(\mathrm{mol} \mathrm{K}))$. There exist many activation energy values as proposed by different research efforts. These values range from $E_{A}=26700$ to $E_{A}=67000 \mathrm{~J} / \mathrm{mol}$ and seem to vary depending on the type of materials used in the mixture [23]. The fact that the values of the apparent activation energy exhibit a wide scatter and a dependency on temperature is not surprising if we consider some well-known temperature effects observed in adiabatic hydration tests (section 4.1). A way to directly determine the activation energy consists in performing some adiabatic tests on concrete samples maturing at different temperatures. This can be achieved, for instance, by performing the tests with different initial temperature of fresh concrete [5]. With the presented ANN-based pre-program, the procedure to directly determine the activation energy as proposed by Morabito [5] can be performed.

Therefore, the rate of heat evolution at time $t$ in environmental conditions can be expressed as $Q=f_{A} Q_{a}$.

\section{Results and discussion}

Several studies were done in order to check the adequacy of the proposed program. At the first stage, big concrete cylinder $(h=250 \mathrm{~cm}, \Phi=90 \mathrm{~cm})$ was prepared. Geometry of this test specimens is shown in Fig. 2 and concrete mixture parameters (reference mixture) were as 
follows: $C T=\mathrm{CT} 1, W C=0.67, A C=180 \mathrm{~kg} / \mathrm{m}^{3}, C A=1, T_{i}=28^{\circ} \mathrm{C}$. Here, $T_{i}$ stands for the temperature of the fresh concrete mixture. Temperature profile was measured experimentally with the previously calibrated thermocouples at six points inside concrete cylinder (see Fig. 2). As an addition, environmental temperature was also measured (point 7).

Fig. 2.

\subsection{Example 1. Adequacy of the proposed program}

The objective of the first example was to validate the proposed numerical model. At the first stage, adiabatic hydration curve was calculated with the proposed ANN pre-program on the basis of concrete mixture parameters. Next, calculated adiabatic hydration curve was automatically inserted into the main program and the temperature profile was calculated. Fig. 3a and $3 \mathrm{~b}$ present the temperature distribution within the analyzed system at times $t=10$ hours and $t=100$ hours, respectively. Axial symmetry was considered.

Fig. 3

Fig. $4 \mathrm{a}$ and $4 \mathrm{~b}$ present measured and calculated temperatures at points 3 and 4 , respectively.

Fig. 4

It can be seen from Fig. 4 that calculated temperatures are in good agreement with the experimentally determined temperatures. This indicates that both ANN pre-program and FE main program were able to correctly determine the adiabatic hydration curve and temperature profile, respectively. Maximum difference between experimentally determined and calculated temperatures was about $2^{\circ} \mathrm{C}$. Note, that these results were obtained only on the bases of some well defined and easily obtainable fresh concrete mixture parameters and data about the experimental settings.

In further analysis some minor corrections of the adiabatic hydration curve were done. The calculated and experimentally determined temperatures were almost identical in this case (Fig. $5)$. 
Fig. 5

4.2 Example 2. Influence of the initial concrete temperature and initial temperature of the adiabatic test

The objective of the second example was to show the ability of the proposed numerical model to predict the influence of the initial concrete temperature, $T_{i}$, on the development of the temperature profile in the concrete element. Therefore, four equal concrete mixtures, including reference mixture at $T_{i}=28^{\circ} \mathrm{C}$ (labelled as "exp") with different initial concrete temperatures were analyzed. Fig. $6 \mathrm{a}$ and $6 \mathrm{~b}$ present the influence of the initial concrete temperature on the development of the adiabatic hydration curves and temperature development at point 3 , respectively. It can be seen from Fig. 6 that a change in initial concrete temperature affects the rate of heat development and consequently the development of the temperature inside the concrete element. The higher the fresh concrete temperature becomes the higher and more rapid the rate of the hydration process, which can be seen from adiabatic hydration curves (Fig. 6a). Another important statement results from Fig. 6a. It can be seen that the long-term adiabatic temperature rise is also strongly affected by the initial temperature magnitude. High initial temperatures may cause decreased long-term adiabatic temperature rise as compared to mixtures with lower initial temperatures. This phenomenon is referred as the cross-over effect and was also observed by some other researchers $[8,23]$. It can be seen from Fig. 6a that calculated adiabatic hydration curves correspond to this statement very well too. A reason why the intersection of heat evolution curves occurs could be that at higher temperatures a denser gel is formed around the hydrating cement grains [24]. It can be seen from Fig. $6 \mathrm{~b}$ that the higher the initial rate of hydration becomes the higher the development of in place concrete temperatures $T$ in the middle of the discussed concrete element. Due to the cross-over effect, the temperatures $T$ decrease slowly with the lower initial temperatures.

Fig. 6 
In the next study the robustness of the proposed procedure is verified. The analyses of the same concrete mixture based on adiabatic measurements with four different initial temperatures of the adiabatic test $T_{0}$ were done. In this case it is expected that the results would be the same for all four analyses since the same physical problem was analysed.

Fig. 7 shows the influence of the initial temperature of the adiabatic hydration curve, $T_{0}$, on the development of the temperature profile in the concrete element. It can be seen that the results were almost identical in all four cases. This effect can be explained by the physical meaning of the age conversion factor $f_{A}$ (see Eq. 17), associated with the Arrhenius equation. It converts a curing interval to the equivalent curing interval at the reference temperature. Should the temperature over the curing interval be larger than the reference temperature, then the age conversion factor will be grater than one. Conversely, if the temperature over the curing interval is less than the reference temperature, then the age conversion factor will be less than one.

Fig. 7

\subsection{Example 3. Influence of the amount of cement}

The objective of this example was to show the influence of the amount of cement on the adiabatic temperature rise and corresponding temperature development in concrete element. In this case, all concrete parameters were the same for all mixtures but the amount of cement varied. Fig. $8 \mathrm{a}$ and $8 \mathrm{~b}$ present the influence of the amount of cement on the development of the adiabatic hydration curves and temperature development at point 3 , respectively.

Fig. 8

It can be clearly seen from Fig. 8a that the higher cement content results to more intensive hydration process. It can be also seen that the long term adiabatic temperature rise is strongly affected by this variable. As expected, the higher cement content results in higher long-term adiabatic temperature rise. Therefore, the proposed ANN module was able to correctly predict the influence of the amount of cement on the development of the adiabatic hydration curves. It 
can be seen from Fig. $8 \mathrm{~b}$ that the higher cement content results in higher temperatures in the concrete element. The temperature decrease was similar for all concrete mixtures in this case.

\section{Conclusions}

New numerical procedure for the prediction of temperature development in early age concrete structures is briefly presented. Adiabatic hydration curves, from which internal heat generation is determined, are determined by a computer program, which is based on artificial neural networks. The adiabatic hydration curve is calculated, based on concrete intial parameters, which are easily estimated or predicted. Adiabatic hydration curve is then automatically inserted into the main program, which is used to calculate the temperature profile at an arbitrary point inside the concrete element. The main program is based on a finite element method. Both programs are implemented in Matlab programming environment.

a) The presented ANN-based pre-program allows us to determine the adiabatic heat of hydration curves very accurately. It was shown that the presented ANN model was able to correctly predict adiabatic hydration curves which were previously not used in analysis. The effects of concrete initial parameters were in accordance with the wellknown rules of mix proportioning and other initial characteristics of fresh concrete mixture. Several studies have shown that the learning data is very important and has to be well distributed over the predetermined ranges of values. This does not seem to be a problem, because new adiabatic hydration curves with some other initial parameters of the concrete mixture can easily be included in the learning set in order to expand the range of suitability of ANN to predict the adiabatic hydration curves.

b) The presented ANN-based model allows us to determine the apparent activation energy as proposed by Morabito [5]. However, several studies have shown that the values of the activation energy does not appear to affect the temperature development in concrete structures considerably.

c) With the temperature prediction program developed in this study, the effects of some concrete initial parameters on the development of the temperature at an arbitrary point 
in the concrete element can easily be studied. This can allow concrete structure

designers and contractors to quantify and evaluate the effect of various controllable and uncontrollable parameters on the temperature development in situ.

\section{Acknowledgements}

This work was financially supported by the European Union, European Social Fund., and Ministry of Education, Science and Sport of the Republic of Slovenia under contract 3211-05000556. The support is gratefully acknowledged.

\section{References}

1. Y. Ballim, A numerical model and associated calorimeter for predicting temperature profiles in mass concrete, Cement and Concrete Composites 26 (5) (2004) 695-703.

2. T. Tanabe, M. Kawasumi, M. Yamashita, Thermal stress analysis of massive concrete. Proc. The Seminar for Finite Element Analysis of Reinforced Concrete Structures, Tokyo, 1985.

3. R. Faria, M. Azenha, J.A. Figueiras, Modelling of concrete at early ages: Application to an externally restrained slab, Cement and Concrete Composites 28 (6) (2006) 572-585.

4. F. Hue, G. Serrano, J.A. Bolano, Oresund Bridge. Temperature and cracking control of the deck slab concrete at early ages, Automation in Construction 9 (5-6) (2000) 437445.

5. P. Morabito, Apparent Activation Energy - An example for determination from adiabatic hydration tests, IPACS report BE96-3043/2001:19-2, Lulea, Sweden, 2001.

6. F. Kavčič, Hydration process of cement in concrete at adiabatic conditions (in Slovenian), M.Sc. Thesis, University of Ljubljana, 2000.

7. C. Ammar, P. Dutron, H. Motteu, J. Dubois, La progression des betons et des mortiers par basses temperatures, C.S.T.C. - C.R.I.C. - SECO, Bruxelles, 1973.

8. K. van Breugel, Simulation of Hydration and Formation of Structure of Hardening Cement-Based Materials - HYMOSTRUC, Ph.D Thesis, Second Edition, Delft University of Technology, 1997.

9. D.P. Bentz, CEMHYD3D: A Three-dimensional Cement Hydration and Microstructure Development Modelling Package. Version 3.0, NISRTIR 7232, U.S. Department of Commerce Technology Administration, Gaithersburg, Maryland, 2005.

10. K. Maekava, R. Chaube, T. Kishi, Modelling of Concrete Performance Hydration, Microstructure Formation and Transport, London: E and F SPON, 1999.

11. A.G. Evsukoff, E.M.R. Fairbairn, E.F. Faria, M.M. Silvoso, R.D.T. Filho, Modelling adiabatic temperature rise during concrete hydration: a data minig approach, Computers and Structures 84 (31-32) (2006) 2351-2362.

12. P. Lura, K. van Breugel, Thermal Properties of Concrete: sensitivity studies IPACS report BE96-3843/2001:15-X, Lulea, Sweden, 2001.

13. Standard EUROCODE 2: Design of concrete structures - Part 1-2: General Rules Structural Fire Design.

14. N. Hong-Guang, W. Ji-Zong, Prediction of compressive strength of concrete by neural networks, Cement and Concrete Research 30 (8) (2000) 1245-1250.

15. S. Lai, M. Serra, Concrete strength prediction by means of neural network, Construction and Building Materials 11(2) (1997) 93-98.

16. S.C. Lee, Prediction of concrete strength using artificial neural networks, Engineering Structures 25 (7) (2003) 849-857. 
17. J. Hola, K. Schabowicz, Application of artificial neural networks to determine concrete compressive strength based on non-destructive tests, Journal of Civil Engineering and Management 11 (2005) 23-32.

18. J. Hola, K. Schabowicz, New technique of non-destructive assessment of concrete strength using artificial intelligence, NDT\&E International 38 (4) (2005) 251-259.

19. M.A. Kewalramani, R. Gupta, Concrete compressive strength prediction using ultrasonic pulse velocity through artificial neural networks, Automation in Construction 15 (3) (2006) 374-379.

20. I.B. Topcu, M. Saridemir, Prediction of compressive strength of concrete containing fly ash using artificial neural networks and fuzzy logic, Computational Materials Science 41 (3) (2008) 305-311.

21. L.D. Graham, D.R. Forbes, S.D. Smith, Modeling the ready mix concrete delivery system with neural networks, Automation in Construction 15 (5) (2006) 656-663.

22. G. Trtnik, F. Kavčič, G. Turk, The use of artificial neural networks in adiabatic curves modeling, Automation in Construction 18 (1) (2008) 10-15.

23. A.K. Schindler, T. Dossey, B.F. McCullough, Temperature control during construction to improve the long term performance of portland cement concrete pavements, Texas Department of Transportation, Research project No. 0-1700-2, The University of Texas at Austin, 2002.

24. K. van Breugel, Hydration of Cement-Based Systems - aspects of hydration of cement based systems and possibilities to quantify the evolution of hydration process. IPACS report, BE96-3843/2001:17-6, Lulea, Sweden, 2001. 


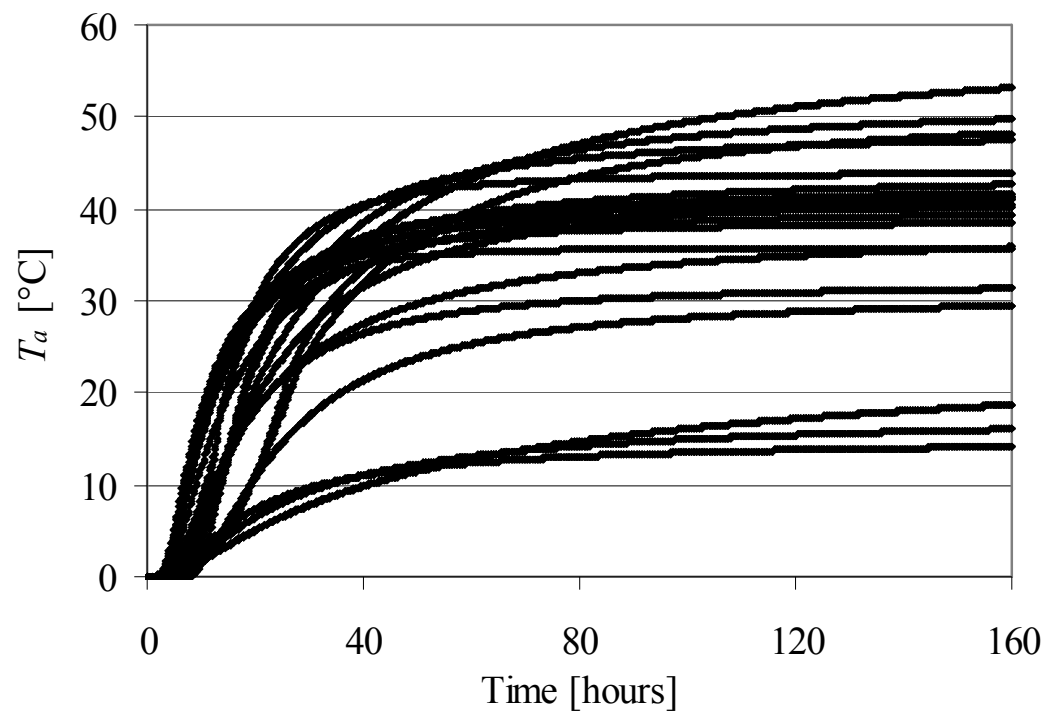

Fig. 1. Some experimentally determined adiabatic hydration curves, used in this study 
a)

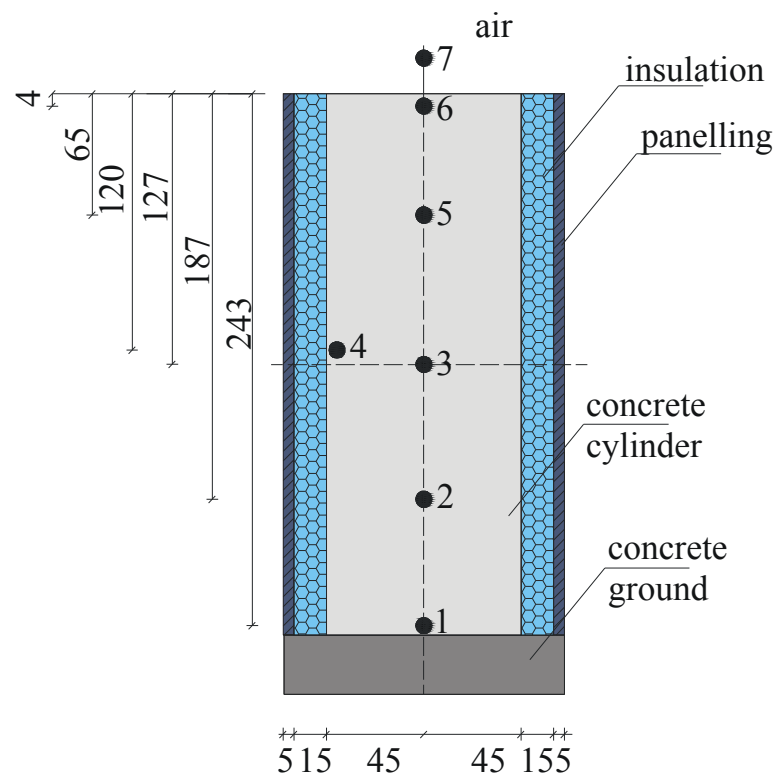

b)

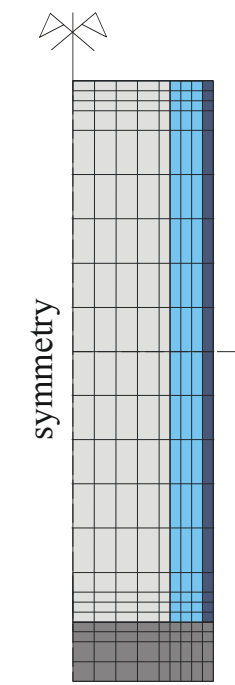

Fig. 2. Showing a) the geometry of the concrete test cylinder with the side insulation and locations of the thermal probes inside the concrete element, b) finite element mesh (axial symmetry) 
a)

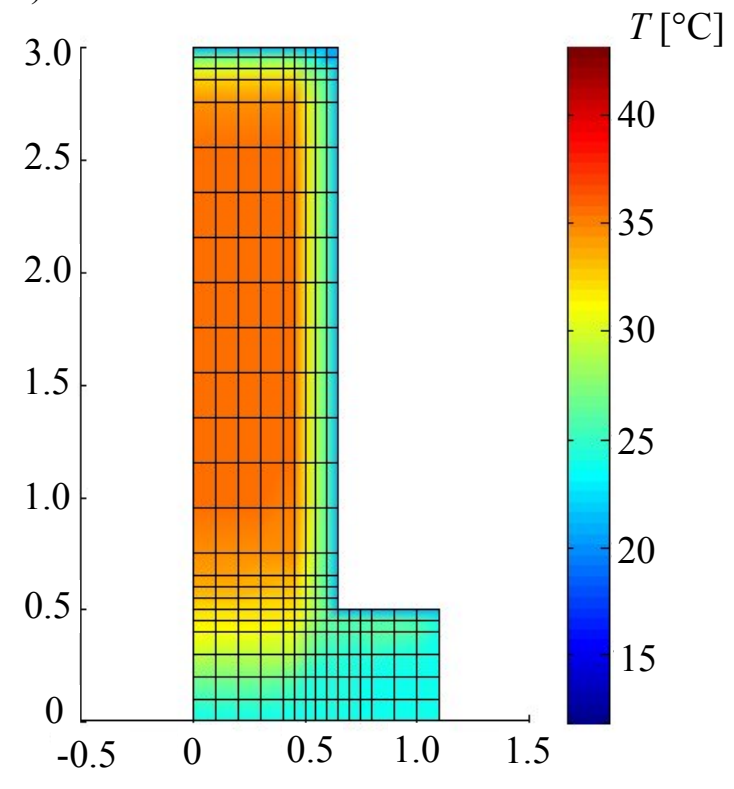

b)

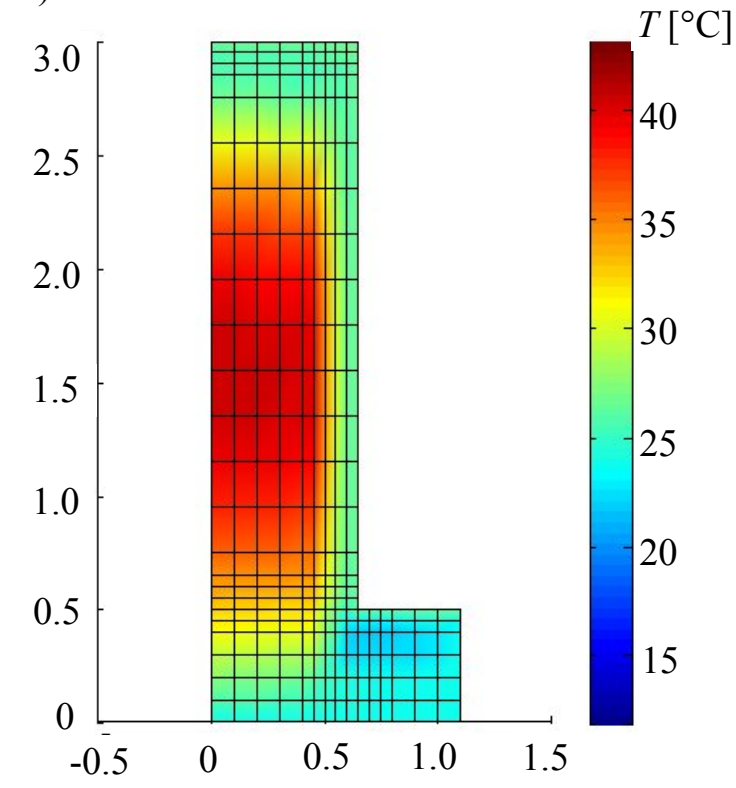

Fig. 3. Calculated temperature distribution within the concrete element at different times, a) $t=10$ hours, b) $t=100$ hours. 
a)

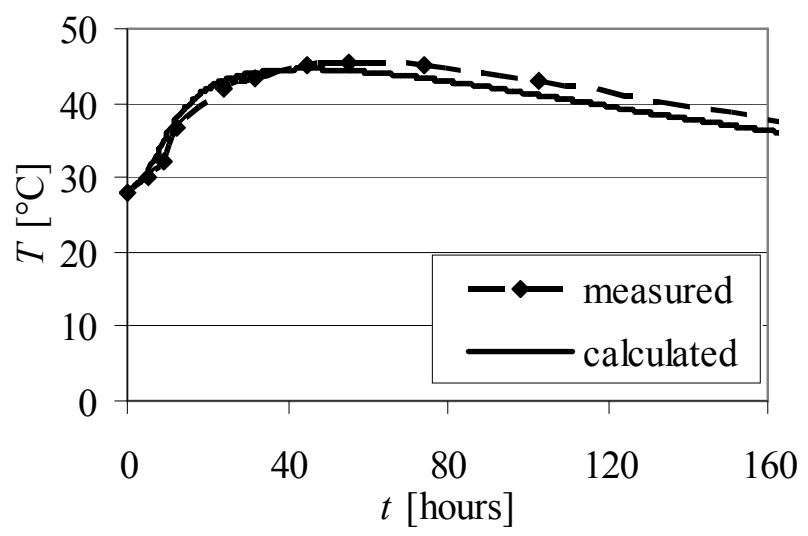

b)

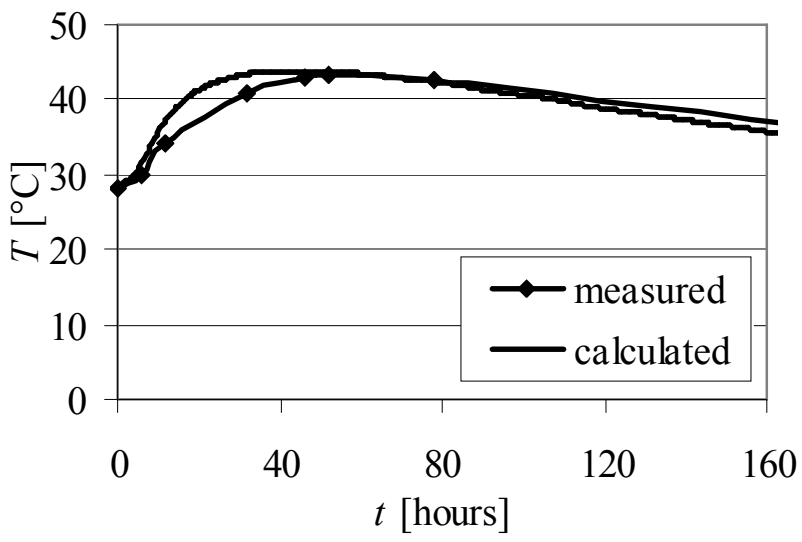

Fig. 4. Adequacy of the proposed numerical model, a) measured and calculated temperature development at point $3, b$ ) measured and calculated temperature development at point 4 . 


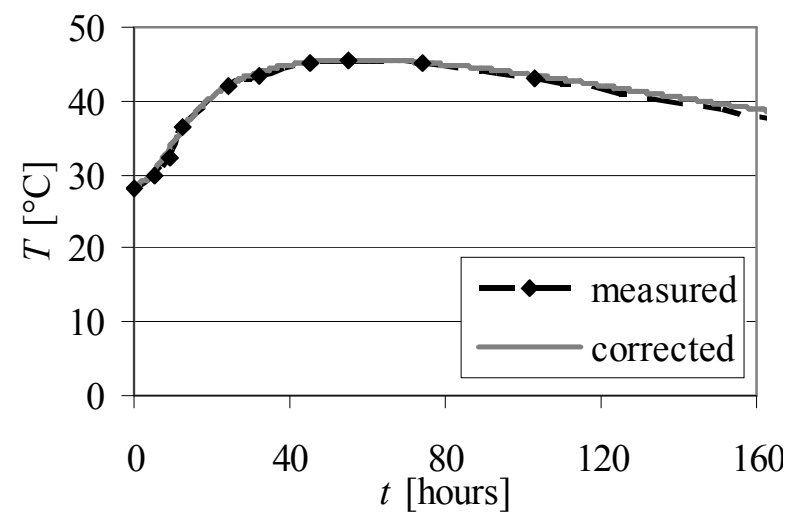

Fig. 5. Actual and calculated temperature development at point 3 after minor corrections of adiabatic hydration curve. 
a)

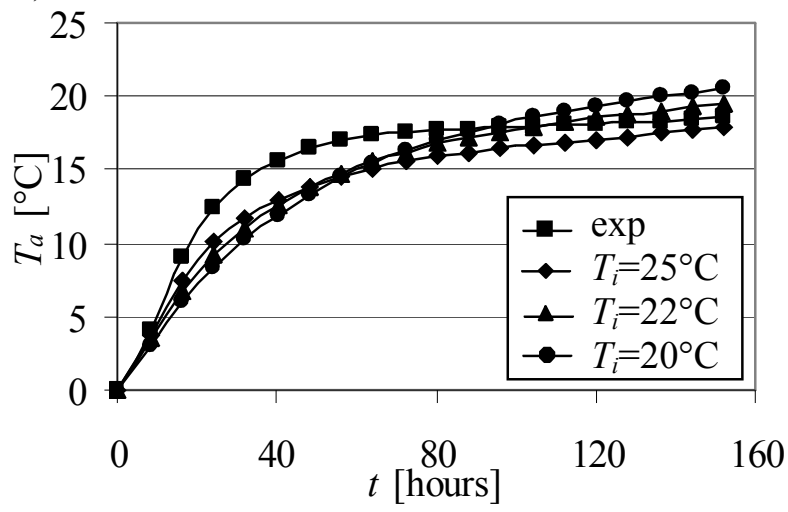

b)

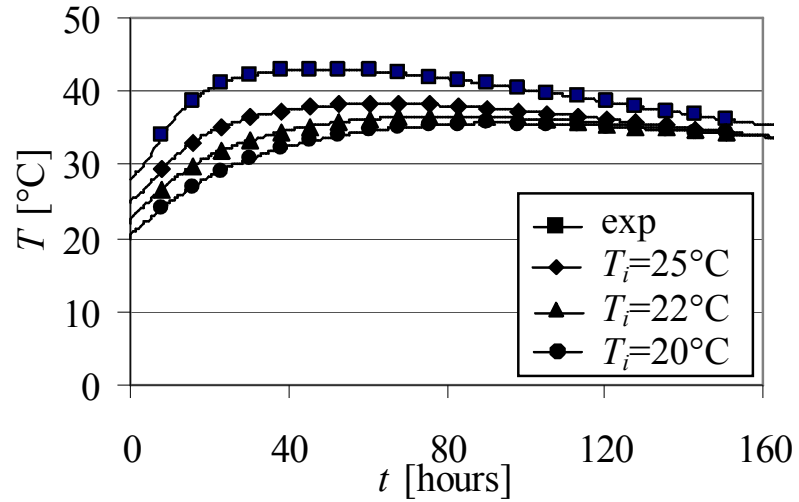

Fig. 6. Influence of the initial concrete temperature on the development of a) adiabatic hydration curve, b) in-place concrete temperature at point 3 . 


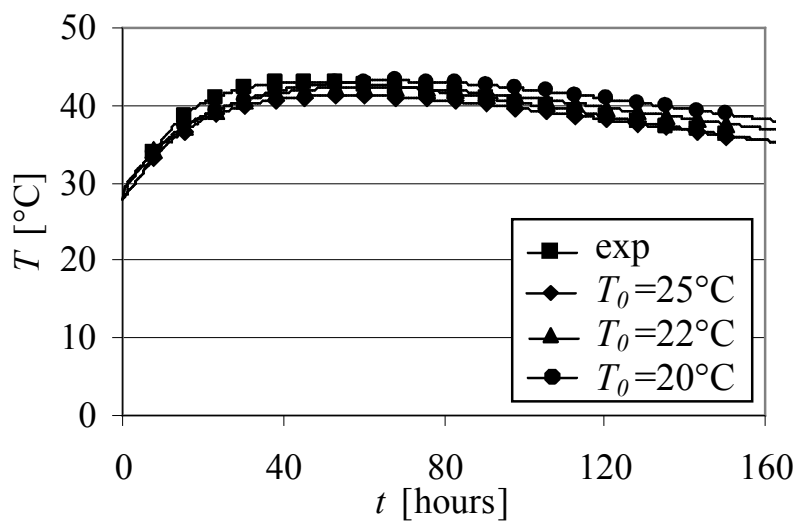

Fig. 7. Influence of the initial temperature at the adiabatic hydration test on the development of the inplace concrete temperature at point 3 . 
a)

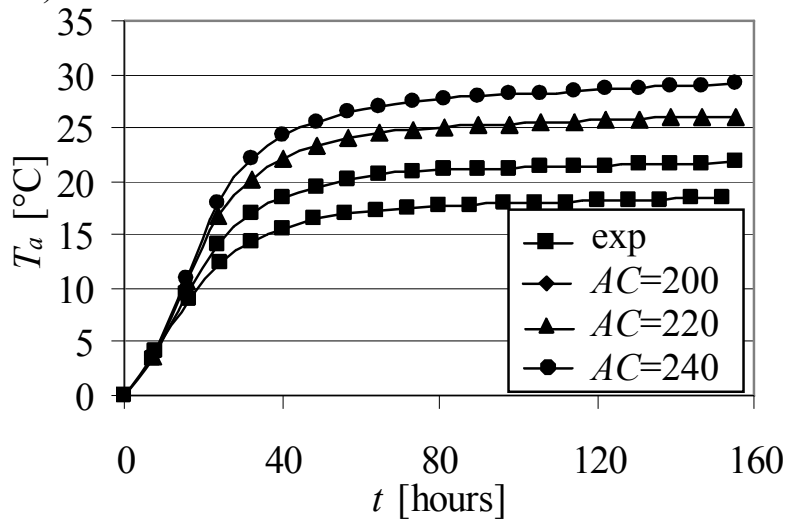

b)

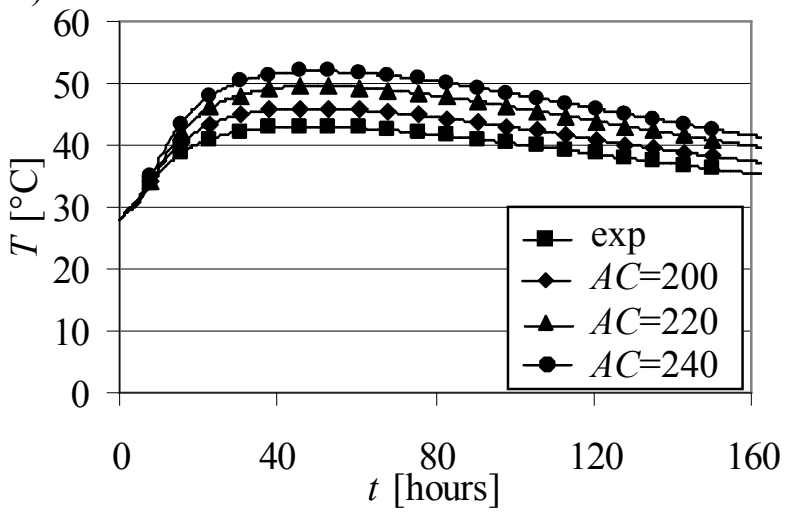

Fig. 8. Influence of the amount of cement on the development of a) adiabatic hydration curve, b) in-place concrete temperature at point 3 . 


\section{Table 1}

Characteristics of all adiabatic hydration curves, used in this study

\begin{tabular}{|c|c|c|c|c|c|c|c|c|c|c|c|}
\hline curve & $C T$ & $W C$ & $\begin{array}{l}\text { paramet } \\
A C \\
{\left[\mathrm{~kg} / \mathrm{m}^{3}\right]}\end{array}$ & $C A$ & $T_{0}\left[{ }^{\circ} \mathrm{C}\right]$ & curve & $C T$ & $W C$ & $\begin{array}{l}\text { paramete } \\
A C \\
{\left[\mathrm{~kg} / \mathrm{m}^{3}\right]}\end{array}$ & $C A$ & $T_{0}\left[{ }^{\circ} \mathrm{C}\right]$ \\
\hline A1 & CT1 & 0.70 & 180 & 1 & 20.0 & A13 & CT3 & 0.47 & 360 & 2 & 7.2 \\
\hline A2 & CT1 & 0.70 & 180 & 1 & 25.0 & A14 & CT3 & 0.50 & 350 & 1 & 22.7 \\
\hline A3 & CT1 & 0.70 & 180 & 1 & 29.0 & A15 & CT3 & 0.50 & 360 & 1 & 23.6 \\
\hline A4 & CT1 & 0.42 & 380 & 1 & 22.9 & A16 & CT3 & 0.50 & 360 & 1 & 24.1 \\
\hline A5 & CT2 & 0.43 & 350 & 1 & 25.3 & A17 & CT3 & 0.54 & 370 & 1 & 17.4 \\
\hline A6 & CT3 & 0.45 & 350 & 1 & 19.9 & A18 & CT3 & 0.54 & 370 & 1 & 13.1 \\
\hline A7 & CT4 & 0.45 & 350 & 1 & 26.5 & A19 & CT3 & 0.54 & 370 & 1 & 7.9 \\
\hline A8 & CT1 & 0.65 & 280 & 1 & 23.0 & A20 & CT3 & 0.50 & 370 & 3 & 18.5 \\
\hline A9 & СТ3 & 0.50 & 360 & 1 & 21.3 & A21 & CT3 & 0.50 & 370 & 3 & 12.8 \\
\hline A10 & СТ3 & 0.50 & 360 & 1 & 22.5 & A22 & CT3 & 0.50 & 370 & 3 & 7.9 \\
\hline A11 & СТ3 & 0.47 & 360 & 2 & 20.7 & A23 & CT3 & 0.52 & 370 & 4 & 19.0 \\
\hline A 12 & CT3 & 0.45 & 330 & 2 & 12.6 & A24 & CT4 & 0.52 & 370 & 4 & 11.0 \\
\hline
\end{tabular}




\section{Table 2}

Values of the calculated ultimate heat of hydration for all cements, used in this study

\begin{tabular}{cc}
\hline cement type & $H_{c e m}[\mathrm{~J} / \mathrm{g}]$ \\
\hline CT1 & 400 \\
CT2 & 370 \\
CT3 & 435 \\
CT4 & 430 \\
\hline
\end{tabular}

